\title{
DENSITOMETRIA ÓPTICA RADIOGRÁFICA NA AVALIAÇÃO DO HIPERPARATIREOIDISMO SECUNDÁRIO NUTRICIONAL INDUZIDO EM GATOS JOVENS
}

\author{
OPTIC DENSITOMETRY IN RADIOGRAPHIC IMAGES TO EVALUATE \\ NUTRITIONAL SECONDARY HYPERPARATHYROIDISM IN KITTENS
}

\author{
Sheila Canevese Rahal ${ }^{1}$ Ana Carolina Mortari ${ }^{2}$ Evelyn Hasegawa Gonçalves Caporali ${ }^{3}$ \\ Luiz Carlos Vulcano ${ }^{3}$ Flávio Augusto Marques dos Santos ${ }^{4}$ \\ Regina Kiomi Takahira ${ }^{5}$ Adalberto José Crocci ${ }^{6}$
}

RESUMO

O trabalho teve por objetivos verificar as alterações da densidade mineral óssea e as alterações bioquímicas, no hiperparatireoidismo secundário nutricional. Foram utilizados 10 gatos, sem raça definida, com idade inicial entre 2 e 3 meses e peso médio de 820 gramas. Após um período de adaptação de 10 dias, eles foram submetidos a uma dieta composta por coração bovino moído e cru durante 60 dias, sendo os exames efetuados no final do período de adaptação e a cada 15 dias. Empregou-se o método de densitometria óptica em imagens radiográficas, do rádio e ulna direitos. Não foi observada diferença estatística na densidade mineral óssea entre o final do período de adaptação e com 15 dias de alimentação com carne de coração. Aos 30 dias, houve uma diminuição significante estatisticamente, que se manteve no mesmo patamar aos 45 e 60 dias. Em nenhum momento de observação ocorreu diferença estatística nos níveis séricos de cálcio e fósforo. Os níveis séricos de fosfatase alcalina variaram e estavam acima dos valores normais no $45^{\circ}$ e $60^{\circ}$ dia da dieta. Foi possível concluir que a densitometria óptica em imagens radiográficas é um método eficiente de avaliação da desmineralização óssea, ao passo que as análises bioquímicas séricas de cálcio, fósforo e fosfatase alcalina são de valor limitado.
Palavras-chave: gatos jovens, hiperparatireoidismo, nutricional, densitometria.

\section{SUMMARY}

The aim of this study was to evaluate the modification of bone mineral density, as well as the serum biochemistry variation in the nutritional secondary hyperparathyroidism. Ten crossbreed cats, initial aging between 2 and 3 months, and weighing 820 grams were used. After 10 days of adaptation, they were fed with raw beef heart for 60 days. At the end of adaptation time and every 15 days, exams were realized. The method of optical densitometry in radiographic images of the right radius and ulna was used. There was no statistical difference in the bone mineral densitometry between the end of adaptation period and with 15 days of consuming a diet of beef heart. At 30 days the bone density decreased statistically, and it was in the same level at 45 and 60 days. There was no statistical difference in the serum calcium and phosphorus concentrations in all observation time. Serum alkaline phosphatase concentration varied and it was increased above normal variation in the $45^{\text {th }}$ and $60^{\text {th }}$ day of the diet. It was possible to conclude that bone densitometry in radiographic

\footnotetext{
${ }^{1}$ Médico Veterinário, Professor Assistente, Doutor, Departamento de Cirurgia e Anestesiologia Veterinária, Faculdade de Medicina Veterinária e Zootecnia (FMVZ), Universidade Estadual Paulista (UNESP), Campus de Botucatu, 18618-000, Rubião Júnior s/n Botucatu, SP. Email:sheilacr@ fmvz.unesp.br. Autor para correspondência

${ }^{2}$ Médico Veterinário, Bolsista de Treinamento Técnico-Nível 3 FAPESP.

${ }^{3}$ Médico Veterinário, Professor Assistente, Doutor, Departamento de Reprodução Animal e Radiologia Veterinária, FMVZ, UNESP, Botucatu.

${ }^{4}$ Médico Veterinário, Mestrando, Departamento de Reprodução Animal e Radiologia Veterinária, FMVZ, UNESP.

${ }^{5}$ Médico Veterinário, Professora Assistente, Doutora, Departamento de Clínica Veterinária, FMVZ, UNESP.

${ }^{6}$ Professor Assistente, Doutor, Departamento de Bioestatística, Instituto de Biociências, UNESP.
} 
images is an efficient method to evaluate bone demineralization, and calcium, phosphorus and alkaline phosphatase serum biochemistry analysis are limited value.

Key words: kittens, hyperparathyroidism, nutritional, densitometry.

\section{INTRODUÇÃO}

O hiperparatireoidismo secundário nutricional tem sido observado mais freqüentemente em filhotes de felinos das raças Siamês e Birmanês (MARTIN \& CAPEN, 1985). A secreção aumentada de paratormônio é conseqüente a dietas que são extremamente baixas em cálcio ou com desequilíbrio cálcio-fósforo, resultante de alta ingestão e absorção de fosfato ou deficiência de vitamina D (CAVANAGH \& KOSOVSKY, 1993). Também tem sido associada a agentes que combinam com o cálcio no intestino (óleo mineral) e previnem a absorção (MANLEY, 1995). Dietas com coração ou fígado contêm, por exemplo, mínimas quantidades de $\mathrm{Ca}$ (7-9mg/100mg) e têm um marcado desequilíbrio Ca e P (1:20-1:50) (MARTIN \& CAPEN, 1985).

Gatos jovens alimentados com coração, conforme (MARTIN \& CAPEN, 1985), desenvolvem distúrbios funcionais dentro de quatro semanas, manifestados por relutância em mover-se, claudicação e modo de andar incoordenado. Após 5 a 14 semanas, as doenças esqueléticas tornam-se mais severas, podendo culminar com a incapacidade de sustentação do próprio esqueleto.

De acordo com HAZEWINKEL (1994), as concentrações de cálcio plasmático são mantidas constantes, ao passo que as de fosfato, sempre mais alto em jovens do que em adultos, são fortemente influenciadas pela alimentação. A fosfatase alcalina estará elevada se houver uma atividade celular óssea aumentada, incluindo o crescimento. Desta forma, a análise desses elementos pode ser de valor limitado no hiperparatireoidismo secundário nutricional (MARTIN \& CAPEN, 1985). A concentração do paratormônio pode também ser aferida, mas requer laboratórios especializados (HAZEWINKEL, 1994).

O método mais prático de diagnóstico, conforme HAZEWINKEL (1994), é a investigação radiológica em ossos longos ou no esqueleto axial. Os sinais radiográficos são osteopenia generalizada, reabsorção da lâmina dental, corticais ósseas finas, fraturas patológicas do ossos longos, lordose da espinha lombar, fratura por compressão da vértebra, retenção colônica, distorção e colapso da pélvis (FARROW, 1982).
SCOTT \& GREAVES (1961) ao alimentarem gatos jovens com uma dieta exclusiva de coração, após uma média de sete semanas, observaram sinais clínicos de nervosismo, ataxia e paralisia dos membros posteriores. A aparência geral era boa, sem perda de apetite; entretanto, o ganho de peso cessou nos gatos mantidos por mais de oito a nove semanas.

PEDERSEN (1983) descreveu cinco casos de hiperparatireoidismo secundário nutricional em gatos Persas, com 17 semanas de idade, alimentados com carne de cavalo crua (90\%) associada à comida para gato e queijo "cottage" (10\%). Os animais mostravam rigidez e claudicação mais evidentes nos membros posteriores, dor, constipação e os músculos abdominais pareciam distendidos e flácidos. A fosfatase alcalina estava elevada de 3 a 6 vezes em relação ao valor normal. Radiograficamente verificou-se osteopenia generalizada, lordose e cifose da coluna cervical, torácica ou lombar e deformação da pélvis.

Seis gatos foram diagnosticados, por TOMSA et al. (1999), com hiperparatireoidismo secundário nutricional, sendo três associados com dieta exclusivamente cárnea, dois com alimentação composta por arroz e carne, e um com dieta de batatas, arroz e cenoura. Os sinais clínicos foram fraturas espontâneas, excitação ou convulsões, que foram atribuídas à severa osteopenia e hipocalcemia. Em relação a gatos controle, os níveis séricos do paratormônio foram muito elevados e da vitamina D3 mediamente elevados.

A densidade e massa mineral óssea podem ser avaliadas usando-se métodos não invasivos, tais como a absorciometria por fóton único, absorciometria por fóton duplo e tomografia computadorizada quantitativa. $\mathrm{O}$ rádio é um local de medida padrão para estudos de absorciometria de fóton única na maioria dos estudos em infantes e crianças, sendo preferível a utilização do meio da diáfise, uma vez que a mudança mineral óssea por milímetro é menor neste local e os erros são reduzidos (BARDEN \& MAZESS, 1988).

CROVACE et al. (1992) determinaram o conteúdo mineral ósseo, mediante densitometria óssea por fóton duplo, em gatos com hiperparatireoidismo secundário nutricional e gatos normais da mesma idade e raça. Todos os animais com a doença, de acordo com a anamnese, eram alimentados exclusivamente com carne vermelha. Os níveis de cálcio, fósforo e fosfatase alcalina estavam normais. $\mathrm{O}$ exame densitométrico mostrou uma marcada redução do conteúdo mineral, sendo o mesmo maior na coluna cérvico-torácica do que na lombar. Concluíram que o exame densitométrico é 
importante para avaliar o dano ósseo real, a severidade da doença e a resposta terapêutica.

A densitometria mineral óssea por imagens radiográficas é uma outra técnica não invasiva que pode ser utilizada na avaliação da densidade óssea. Tem como vantagens o baixo custo, rapidez e simplicidade de execução (LOUZADA, 1994). Atualmente o Serviço de Radiologia de Botucatu tem desenvolvido um sistema computadorizado, o que permite uma maior precisão na leitura da densidade óptica em imagens radiográficas.

Em virtude do exposto, o trabalho teve por objetivos avaliar, por meio de densitometria óptica por imagens radiográficas, a desmineralização óssea induzida experimentalmente em gatos, bem como a determinação das alterações bioquímicas.

\section{MATERIAL E MÉTODOS}

Foram utilizados 10 gatos, sem raça definida, cinco machos e cinco fêmeas, com idade aproximada inicial entre 2 e 3 meses e peso médio de 820 gramas, numerados aleatoriamente de 1 a 10 , que foram alocados dois a dois em jaulas de $60 \times 49 \times 52 \mathrm{~cm}$, recebendo água e alimentação ad libitum. Após vermifugação e vacinação, os animais foram submetidos a um período de adaptação de 10 dias, no qual receberam um mesmo tipo de ração comercial para filhotes, considerada de boa qualidade. Posteriormente, foram alimentados por 60 dias com coração de boi moído e cru, visando à indução de hiperparatireoidismo secundário nutricional.

Os gatos foram pesados e submetidos a exames físicos no início e término do período de adaptação e, semanalmente, até o $60^{\circ}$ dia do experimento. Os níveis de cálcio, fósforo e fosfatase alcalina no soro e a densitometria óptica radiográfica, foram realizados no final do período de adaptação (M1) e, a cada período de quinze dias, até o término do experimento (M2 até M5).

O exame densitométrico foi efetuado acima da zona metafisária do rádio e ulna direitos, em posição crânio-caudal (Figura 1). A medida da densidade mineral óssea, em milímetros de alumínio $(\mathrm{mmAl})$, foi realizada por meio de um programa computacional (software $^{\mathrm{a}}$ ) desenvolvido para medida da densidade óptica em filmes de raios- $\mathrm{X}$ contendo as imagens radiográficas do rádio e ulna, região de partes moles adjacentes e escala de alumínio ("phanthom").
Foi utilizada a análise estatística de medidas repetidas (MORRISON, 1990) visando a comparação, em média, entre os vários momentos durante a indução do hiperparatireiodismo secundário nutricional. $\mathrm{O}$ nível de significância adotado foi de $5 \%$ de probabilidade.

\section{RESULTADOS}

Com exceção do gato $\mathrm{n}^{\mathrm{0}}$ 10, a dieta com coração de boi cru foi rapidamente aceita, tendo os animais apresentado inicialmente um apetite voraz. No final do primeiro mês de indução, os animais $n^{\circ} 3$ e 10 apresentaram moderada redução de apetite, que normalizou após dois dias. As fezes tornaram-se fluídas e de coloração enegrecida na primeira semana. Posteriormente, variaram de consistência firme a semipastosa, mantendo a coloração escura até o término do experimento. $\mathrm{O}$ pêlo tornou-se brilhante e macio. Todos os animais apresentaram um ganho de peso progressivo, sendo em média 275 gramas a cada período (Tabela 1 ).

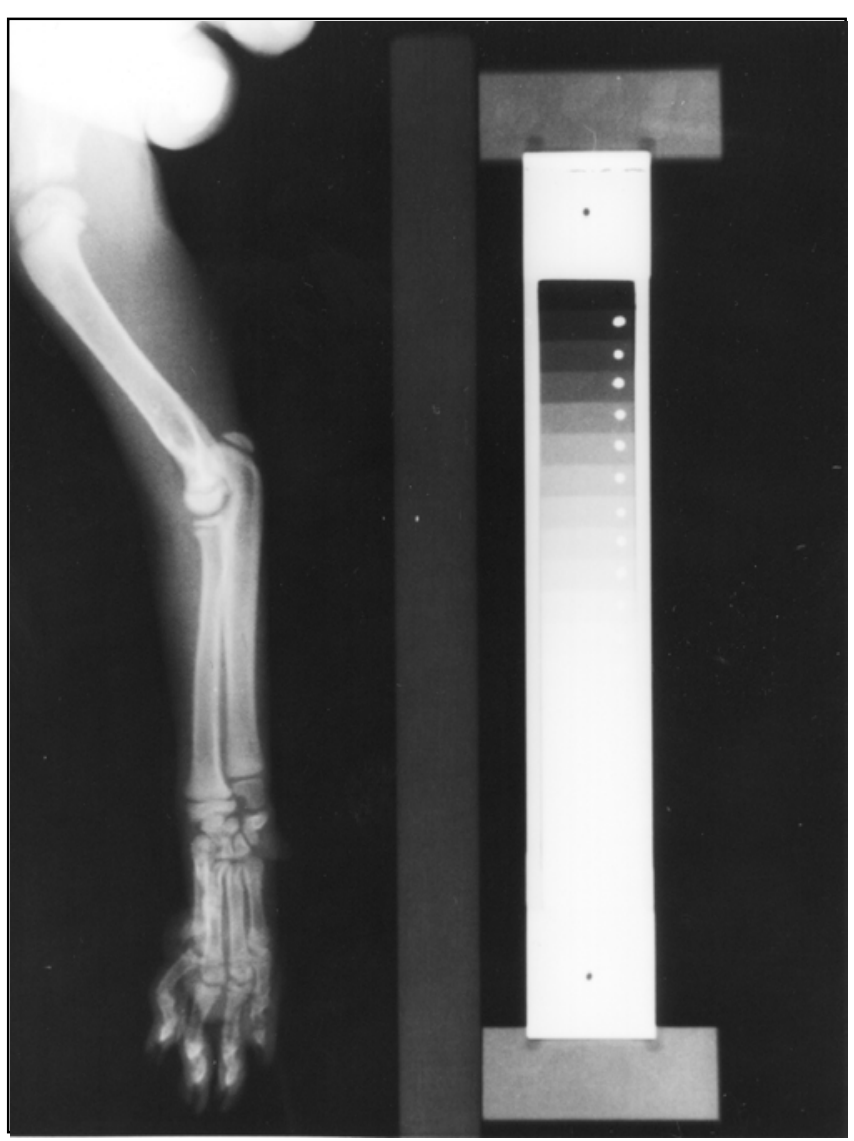

Figura 1 - Aspecto radiográfico do rádio e ulna, em gato posicionado para exame densitométrico, aos 30 dias de dieta com coração bovino. 
Tabela 1 - Médias (Desvio Padrão) das variáveis (densitometria óssea, ganho de peso, Fosfatase Alcalina, Cálcio, Fósforo) observadas nos animais submetidos ao hiperparatireoidismo secundário nutricional (grupo II), segundo momentos de avaliação M1 (final do período de adaptação - dia 0), M2 (15 dias), M3 (30 dias), M4 (45 dias) e M5 (60 dias).

\begin{tabular}{|c|c|c|c|c|c|}
\hline \multirow[b]{2}{*}{ VARIÁVEIS } & \multicolumn{5}{|c|}{ MOMENTOS } \\
\hline & M1 & M2 & M3 & M4 & M5 \\
\hline $\begin{array}{l}\text { Densitometria óssea } \\
(\mathrm{mmA} \ell)\end{array}$ & $1,28(0,19) \mathrm{A}^{*}$ & $1,24(0,18) \mathrm{A}$ & $1,00(0,18) \mathrm{B}$ & $1,06(0,14) \mathrm{B}$ & $1,05(0,17) \mathrm{B}$ \\
\hline Peso (kg) & $0,84(0,15) \mathrm{A}$ & $1,14(0,25) \mathrm{B}$ & $1,56(0,26) \mathrm{C}$ & $1,79(0,29) \mathrm{D}$ & $1,94(0,31) \mathrm{E}$ \\
\hline $\begin{array}{l}\text { Fosfatase alcalina } \\
(\mathrm{UI} / \ell)\end{array}$ & 246,5(198)A & $127,6(71,6) \mathrm{C}$ & 281,7(176)A & $399,9(140,8) \mathrm{B}$ & $448,7(11,9) \mathrm{B}$ \\
\hline Cálcio (mg/d $\ell)$ & $9,3(1,32) \mathrm{A}$ & $9,4(0,55) \mathrm{A}$ & $10,82(2,55) \mathrm{A}$ & $9,3(0,32) \mathrm{A}$ & $9,49(0,67) \mathrm{A}$ \\
\hline Fósforo $(\mathrm{mg} / \mathrm{d} \ell)$ & $7,16(1,29) \mathrm{A}$ & $7,36(0,8) \mathrm{A}$ & $7,72(0,8) \mathrm{A}$ & $8,12(0,6) \mathrm{A}$ & $7,35(2,42) \mathrm{A}$ \\
\hline
\end{tabular}

*Para cada variável avaliada, médias de momentos seguidas de letras iguais não diferem significativamente $(\mathrm{P}>0,05)$.

Os gatos $\mathrm{n}^{\mathrm{0}} 4$ e 7 , na segunda metade da sexta semana do período de alimentação com carne, tornaram-se menos ativos e com sensibilidade nos membros posteriores. $\mathrm{O}$ animal $\mathrm{n}^{\mathrm{0}} 7$ claudicou, de forma intermitente, com o membro anterior esquerdo a partir da sétima semana de indução. Na última semana do experimento ambos permaneceram a maior parte do tempo deitados, sendo que o animal $\mathrm{n}^{\circ} 4$ recusou-se a apoiar o membro posterior esquerdo no solo e defecou e urinou deitado. Ambos apresentaram hiporexia nesse período. $\mathrm{O}$ exame radiográfico revelou lordose da espinha lombar, fraturas do acetábulo esquerdo, na $5^{\mathrm{a}}$ e $6^{\mathrm{a}}$ vértebras lombares no gato $\mathrm{n}^{\circ} 4$ e na $4^{\text {a }}$ vértebra lombar, no gato $\mathrm{n}^{-} \mathrm{7}$.

O animal $\mathrm{n}^{\mathrm{0} 8}$, durante o início da sexta semana de indução do hiperparatireoidismo secundário nutricional, começou a apresentar claudicação intermitente em membro anterior esquerdo. $\mathrm{O}$ quadro persistiu durante dois dias e cessou. Ao redor da sétima semana, manifestou claudicação no membro posterior esquerdo e, a partir da oitava semana, dor severa à palpação de ambos os membros posteriores, permanecendo grande parte do tempo sentado ou deitado e relutando em caminhar ou realizar exercícios até o término do experimento. $\mathrm{O}$ gato $\mathrm{n}-10$ manifestou dor e claudicação em membro posterior esquerdo apenas nos últimos dias do experimento.

Radiograficamente foi observada osteopenia generalizada e corticais ósseas finas em todos os animais, especialmente na última avaliação; no entanto, fraturas patológicas foram detectadas apenas nos gatos no-4 e 7. Não ocorreu diferença estatisticamente significante na densitometria óssea entre o final do período de adaptação e com 15 dias de dieta com coração bovino. Aos 30 dias, houve uma diminuição na densidade óssea, que se manteve no mesmo patamar aos 45 e 60 dias (Tabela 1).

Em todos os momentos de avaliação, não ocorreu diferença estatisticamente significante nos níveis séricos de cálcio, fósforo (Tabela 1). Os níveis séricos de fosfatase alcalina sofreram uma queda entre $o$ primeiro $\mathrm{e}$ o segundo momento e, no momento seguinte, retornaram ao índice inicial. No momento 4, houve um aumento significante nesses níveis e bem acima dos valores normais, mantendo-se neste patamar até a última colheita de sangue (Tabela 1).

\section{DISCUSSÃO}

A dieta com coração de boi cru, como também verificado por SCOTT \& GREAVES (1961), foi aceita rapidamente pelos animais, que apresentaram inicialmente apetite voraz, ganho de peso e boa aparência geral. Por outro lado, em virtude do marcado desequilíbrio cálcio e fósforo (MARTIN \& CAPEN, 1985; CAVANAGH \& KOSOVSKY, 1993) permitiu, como citado por MARTIN \& CAPEN (1985), a indução do hiperparatireoidismo secundário nutricional. $\mathrm{O}$ início da manifestação clínica da doença ocorreu a partir da sexta semana, semelhante ao observado por SCOTT \& GREAVES (1961) e superior ao período de quatro semanas citado por MARTIN \& CAPEN (1985).

Os sinais clínicos, tais como claudicação, relutância na locomoção e sensibilidade nos membros, foram compatíveis ao referido por outros autores (SCOTT \& GREAVES, 1961; MARTIN \& CAPEN, 1985; PEDERSEN, 1983; TOMSA et al., 1999), mas foram detectados em apenas quatro animais.

Os valores bioquímicos de cálcio e fósforo, além de não terem diferido estatisticamente nos vários momentos da dieta com coração bovino, apresentaram-se dentro dos valores considerados normais para animais jovens (CRAWFORD, 1990), o que corrobora as afirmações de outros autores (MARTIN \& CAPEN, 1985; CROVACE et al., 1992; HAZEWINKEL, 1994), que as concentrações 
plasmáticas desses elementos contribuem pouco para o diagnóstico. Por sua vez, os níveis séricos de fosfatase alcalina que, quando elevados, podem ser um indicador de atividade osteoclástica (HAZEWINKEL, 1994), mostraram-se bastante variáveis e com valores em torno de 1,3 a 1,7 vezes acima do normal (PIECHOTTA \& KOLB, 1994), especialmente no $45^{\circ}$ e $60^{\circ}$ dia com a dieta. Este fato também foi observado por PEDERSEN (1983), em casos clínicos de hiperparatireoidismo secundário nutricional; entretanto, o aumento foi de 3 a 6 vezes em relação ao normal. A análise das concentrações do hormônio da paratireóide, como verificado por TOMSA et al. (1999), pode ser de valor diagnóstico, mas requer laboratórios especializados (HAZEWINKEL, 1994) e o custo é elevado. Embora CROVACE et al. (1992) tenham utilizado a coluna para realização de exames densitométricos em gatos com hiperparatireoidismo secundário nutricional, a escolha dos ossos do rádio e ulna, como o local de medida padrão, também permitiu a detecção das variações da mineralização óssea. Mesmo com a citação de BARDEN \& MAZESS (1988), que aferições no meio da diáfise do rádio são mais precisas por ser a mudança mineral óssea menor neste local, utilizou-se acima da metáfise porque o programa utilizado somente permite leitura neste local.

$\mathrm{O}$ exame de densitometria mineral óssea mostrou a maior alteração da mineralização óssea ao 30 dias da dieta com coração e manteve-se no mesmo patamar aos 45 e 60 dias, permitindo um diagnóstico anterior ao início dos sinais clínicos. Os sinais radiográficos de osteopenia generalizada e corticais ósseas finas verificados, especialmente na última avaliação dos animais, bem como fraturas patológicas e lordose nos gatos $\mathrm{n}^{\circ} 4$ e 7 , são indícios do hiperparatireoidismo (HAZEWINKEL 1994; FARROW, 1982; PEDERSEN 1983). No entanto, o exame de densitometria mineral óssea comparativamente ao radiográfico simples, permitiu a quantificação da lesão, fato também observado por CROVACE et al. (1992) ao empregar a densitometria por fóton duplo, sendo um dado importante para o acompanhamento evolutivo da doença. Além disso, como citado por LOUZADA (1994), foi de execução rápida e fácil, não necessitando tranqüilização ou anestesia dos animais.

\section{CONCLUSÕES}

Foi possível concluir que a densitometria óssea em imagens radiográficas é um método eficiente de avaliar a desmineralização óssea ocorrida no hiperparatireoidismo secundário nutricional, ao contrário das avaliações bioquímicas séricas de cálcio, fósforo e fosfatase alcalina.

\section{FONTES DE AQUISIÇÃO}

a - ATHENA - SAI - Sistema de Inteligência Avançada Com. Imp. Exp. Ltda - São José dos Campos, SP.

\section{REFERÊNCIAS BIBLIOGRÁFICAS}

BARDEN, H.S., MAZESS, R.B. Bone densitometry in infants. J Pediatr, v.113, n.1, p.172-177, 1988.

CAVANAGH, P.G., KOSOVSKY, J.E. Hyperparathyroidism and metabolic bone disease. In: BOJARAB, M.J., SMEAK, D.D., BLOOMBERG, M.S. Diseases mechanisms in small animal surgery. Philadelphia : Lea \& Febiger, 1993. Cap.120, p.869-871.

CRAWFORD, M.A. The urinary system. In: HOSKINS, J.D. Veterinary pediatrics. Philadelphia : Saunders, 1990. Cap.10. p.271-92.

CROVACE A., BELLO A., MASTRONARDI M. Studio delliperparatiroidismo secondario alimentare del gatto mediante la densitometria ossea bifotonica computerizzata. Documenti Veterinari, v.13, n.10, p.61-4, 1992.

FARROW C.S. Exercise in diagnostic radiology. Can Vet J, v.23, p.253-254, 1982.

HAZEWINKEL, H.A.W. Skeletal disease. In: WILLS, J.M., SIMPSON, K.W. The Waltham book of clinical nutrition of the dog and cat. Great Britain : Pergamon, 1994. Cap.22. p.395-423.

LOUZADA, M.J.Q. Otimização da técnica de densitometria óptica em imagens radiográficas de peças óssea. Estudo "in vitro". Campinas, 1994. 191p. Tese (Doutorado em Engenharia Biomédica) - Faculdade de Engenharia Elétrica, Universidade Estadual de Campinas, 1994.

MARTIN, S.L., CAPEN, C.C. The endocrine system. In: PRATT, P.W. Feline medicine. Santa Barbara : American Veterinary, 1985. Cap.11. p.340-344.

MANLEY, P. Diseases affecting bone. I n: OLMSTEAD, M.L. Small animal orthopedics. St. Louis : Mosby, 1995. Cap.20, p.432-433.

MORRISON, D.F. Multivariate statistical methods. São Paulo: Mc Graw-Hill, 1990. 450p.

PEDERSEN, N.C. Nutritional secondary hyperparathyroidism in a cattery associated with the feeding of a fad diet containing horsemeat. Feline Pract, v.13, n.6, p.19-26, 1983.

PIECHOTTA, D., KOLB, E. Die konzentration an Na, K, Ca, $\mathrm{Mg}$, anorganischem Phosphat, $\mathrm{Cu}$ und $\mathrm{Zn}$, sowie die aktivität der alkalischen phosphatase im plasma von katzen unterschiedlichen alters. Tierärztl Umschau, v.49, p.439444, 1994

SCOTT, P.P., GREAVES, J.P. Nutrition of the cat. Brit J Nutr, v.15, p.35-51, 1961.

TOMSA, K., GLAUS, T., HAUSER, B., et al. Nutritional secondary hyperparathyroidism in six cats. J Small Anim Pract, v.40, n.11, p.533-539, 1999. 